Kansas State University Libraries

New Prairie Press

\title{
A STUDY OF THE STATISTICAL PROPERTIES OF TWO MEASURES OF COMPETITION
}

Ann L. Oberg

Linda J. Young

Leon G. Higley

Follow this and additional works at: https://newprairiepress.org/agstatconference

Part of the Agriculture Commons, and the Applied Statistics Commons

\section{(c) (1) $\Theta(9$}

This work is licensed under a Creative Commons Attribution-Noncommercial-No Derivative Works 4.0 License.

\section{Recommended Citation}

Oberg, Ann L.; Young, Linda J.; and Higley, Leon G. (1994). "A STUDY OF THE STATISTICAL PROPERTIES OF TWO MEASURES OF COMPETITION," Conference on Applied Statistics in Agriculture. https://doi.org/ $10.4148 / 2475-7772.1347$

This is brought to you for free and open access by the Conferences at New Prairie Press. It has been accepted for inclusion in Conference on Applied Statistics in Agriculture by an authorized administrator of New Prairie Press. For more information, please contact cads@k-state.edu. 


\title{
A STUDY OF THE STATISTICAL PROPERTIES OF TWO MEASURES OF COMPETITION
}

\author{
Ann L. Oberg ${ }^{1}$, Linda J. Young ${ }^{1}$, Leon G. Higley ${ }^{2}$ \\ ${ }^{1}$ Biometry Department and ${ }^{2}$ Entomology Department \\ University of Nebraska - Lincoln \\ Lincoln, NE 68583-0712
}

Abstract

In competition studies, two species are studied, generally in ratios of 1:0, 3:1, 1:1, 1:3, and $0: 1$. The standard measure of competition is the Relative Crowding Coefficient $(\mathrm{RCC})$

$$
\frac{\bar{X}_{1: 1} / \bar{Y}_{1: 1}}{\bar{X}_{1: 0} / \bar{Y}_{0: 1}}
$$

where $\mathrm{X}_{\mathrm{i}: \mathrm{j}}\left(\mathrm{Y}_{\mathrm{i}: \mathrm{j}}\right)$ is the mean biomass for species $\mathrm{X}(\mathrm{Y})$ when the ratio of $\mathrm{X}$ to $\mathrm{Y}$ is $\mathrm{i}$ to j. Novak et al. (1993 Environmental Entomology) proposed the alternative measure

$$
\frac{\frac{1}{3}\left[\frac{1}{3}\left(\frac{\bar{X}_{3: 1}}{\bar{Y}_{3: 1}}\right)+\left(\frac{\bar{X}_{1: 1}}{\bar{Y}_{1: 1}}\right)+3\left(\frac{\bar{X}_{1: 3}}{\bar{Y}_{1: 3}}\right)\right]}{\left(\frac{\bar{X}_{1: 0}}{\bar{Y}_{0: 1}}\right)}
$$

For each, a value of 1 indicates the two species are equal competitors. Values greater than (less than) 1 indicate species $\mathrm{X}(\mathrm{Y})$ is out-competing species $\mathrm{Y}(\mathrm{X})$. However, tests to determine whether the measures are significantly different from 1 have not been proposed. The approximate properties of the RCC are given in Rao and Pereira (1968 Sankhya A). Those for the alternative index are derived by extending this work. Based on the results, tests of significance are proposed. The adequacy of these tests is assessed in a Monte Carlo study.

Key words: species competition, Relative Crowding Coefficient (RCC), Monte Carlo simulation, bootstrap

1. Introduction.

Competition refers to the ability of species to compete with one another for limited resources. As an example, consider the larval competition of two species of mosquitoes, Aedes albopictus and Aedes triseriatus. A. triceriatus is an indigenous mosquito species while A. albopictus was introduced into North America from southeast Asia. Both species are vectors of several disease-causing viruses, including the LaCrosse encephalitis virus (LAC). While A. triceriatus restricts its travel to within 100 yards or so from its home, 
A. albopictus may travel several miles from its home. Because this enhances its ability to transmit disease, A. albopictus is both an environmental and a medical concern. Both species require a similar habitat leading to competition. Major problems can arise if $A$. albopictus consistently "out-competes" A. triceriatus. Replacement series experiments were conducted to evaluate the larval competition of these two species. The replacement series experiments consisted of a factorial treatment structure in a randomized complete block design (RCBD) with four replications. There were ten treatments consisting of five replacement series ratios $(1: 0,3: 1,1: 1,1: 3$, and $0: 1)$ with two diets per ratio (low and high).

Data arising from replacement series experiments are used to estimate the effect of competition between the species. The Relative Crowding Coefficient (RCC) is typically used as the measure of competition. The standard method of estimating RCC uses the ratios $0: 1,1: 1$, and 1:0, but does not include the information from the 1:3 and 3:1 ratios. Novak et al. (1993) proposed an alternative measure of RCC that uses data from all five ratios. For each measure, an RCC of 1 indicates no competition. However, no test of the hypotheses $\mathrm{H}_{0}:$ RCC $=1$ vs. $\mathrm{H}_{1}$ : $\mathrm{RCC} \neq 1$ has been presented in the biological literature. Although approximations of the bias and variance for the standard RCC measure may be found in the statistical literature (Rao and Pereira, 1968), these approximations have not been given for the alternative RCC measure. This paper will develop formulae for the approximate bias and variance of the alternative RCC measure. Further, possible tests of the hypothesis of no competition will be introduced and assessed in a Monte Carlo study.

\section{Replacement Series Experiment}

Replacement series experiments are a standard method used in the evaluation of competition. In such an experiment, the proportions of the two species $\mathrm{X}$ and $\mathrm{Y}$ present in the mixture are varied while the total density $\mathrm{X}+\mathrm{Y}$ is held constant throughout the experiment (Harper 1977). Typically, the ratios are 0:1, 1:3, 1:1, 3:1, and 1:0. Due to the expense of conducting these studies, the number of replications tends to be small.

Four possible models may be observed in such an experiment (Harper 1977). In Model I, competition is such that either the species do not interfere with one another, or, the effect of intra- and inter-species competition are the same (the effect of $\mathrm{X}$ on $\mathrm{Y}$ is the same as that of $\mathrm{Y}$ on $\mathrm{Y}$ and the effect of $\mathrm{Y}$ on $\mathrm{X}$ is the same as that of $\mathrm{X}$ on $\mathrm{X}$ ). The two species $\mathrm{X}$ and $\mathrm{Y}$ contribute to the total yield in direct ratio to their proportion in the colony (see Figure 1).

In the remaining models, competition is evident. In Model II, the effect of $X$ on $\mathrm{Y}$ is greater than that of $\mathrm{Y}$ on $\mathrm{Y}$ and the effect of $\mathrm{Y}$ on $\mathrm{X}$ is less than that of $\mathrm{X}$ on $\mathrm{X}$. Thus species $\mathrm{Y}$ is suffering the most from the presence of $\mathrm{X}$ in the mixture (see Figure 2).

Model III is a case where neither species contributes its expected share to the total 
yield. The effect of $\mathrm{X}$ on $\mathrm{Y}$ is greater than that of $\mathrm{Y}$ on $\mathrm{Y}$ and the effect of $\mathrm{Y}$ on $\mathrm{X}$ is greater than that of $\mathrm{X}$ on $\mathrm{X}$. That is, both species harm the environment of the other more than its own (see Figure 3).

Model IV arises when both species produce more than expected. This is because the effect of $\mathrm{X}$ on $\mathrm{Y}$ is less than that of $\mathrm{Y}$ on $\mathrm{Y}$ and the effect of $\mathrm{Y}$ on $\mathrm{X}$ is less than that of $\mathrm{X}$ on $\mathrm{X}$. Although this may appear to be a case of symbiosis, this is not necessarily true. It is only necessary for neither species to suffer as much as expected from the presence of the other (see Figure 4).

\section{Standard Relative Crowding Coefficient $\left(\mathrm{RCC}_{1}\right)$}

The traditional estimate of the relative crowding coefficient, $\mathrm{RCC}_{1}$, makes use of the $1: 0,1: 1$, and $0: 1$ ratios to estimate competition in the following way:

$$
R \hat{C} C_{1}=\frac{\bar{X}_{1: 1} / \bar{Y}_{1: 1}}{\bar{X}_{1: 0} / \bar{Y}_{0: 1}}
$$

Rao and Pereira, 1968 (see also Cochran, 1977) determined variance and bias of a double ratio estimator to order $n^{-1}$. Replacing population estimates with sample estimates gives an estimated variance of

$$
\operatorname{Vâr}\left(R \hat{C} C_{1}\right)=\frac{R \hat{C} C_{1}^{2}}{n}\left(\frac{S^{2}{ }_{1: 1}}{\bar{Y}^{2}{ }_{1: 1}}+\frac{S^{2}{ }_{X_{1: 1}}}{\bar{X}^{2}{ }_{1: 1}}-\frac{2 S_{X_{1: 1} Y_{1: 1}}}{\bar{X}_{1: 1} \bar{Y}_{1: 1}}+\frac{S_{Y_{0: 1}}^{2}}{\bar{Y}_{0: 1}^{2}}+\frac{S^{2}{ }_{X_{1: 0}}}{\bar{X}^{2}{ }_{1: 0}}\right)
$$

and estimated bias

$$
\operatorname{BI\hat {A}S}\left(R \hat{C} C_{1}\right)=\frac{R \hat{C} C_{2}}{n}\left(\frac{S^{2}{ }_{1: 1}}{\bar{Y}^{2}{ }_{1: 1}}+\frac{S^{2} X_{1: 0}}{\bar{X}^{2}{ }_{1: 0}}-\frac{S_{X_{1: 1} Y_{1: 1}}}{\bar{X}_{1: 1} \bar{Y}_{1: 1}}\right)
$$

where $\bar{X}_{\mathrm{i}: \mathrm{j}}\left(\overline{\mathrm{Y}}_{\mathrm{i}: \mathrm{j}}\right)$ is the estimated mean biomass for species $\mathrm{X}(\mathrm{Y})$ when the ratio of $\mathrm{X}$ to $\mathrm{Y}$ is $\mathrm{i}$ to $\mathrm{j}, S_{X_{i: j}}{ }^{2}\left(S_{Y_{i: j}}{ }^{2}\right)$ is the estimated variance of $\mathrm{X}(\mathrm{Y})$ at the ratio $\mathrm{i}$ to $\mathrm{j}$, and $S_{X_{i: j} Y_{i: j}}$ is the estimated covariance of $X$ and $Y$ at the ratio of $i$ to $j$. A value of 1 indicates a case of no competition while a value greater than 1 would indicate that species $\mathrm{X}$ "out competes" species Y. Note that this standard estimator does not make use of all of the information from the experiment; the ratios $3: 1$ and 1:3 are not used.

\section{Alternative Relative Crowding Coefficient $\left(\mathrm{RCC}_{2}\right)$}

An alternative measure of the relative crowding coefficient, $\mathrm{RCC}_{2}$, introduced in Novak, et.al. (1993) is as follows: 


$$
R \hat{C} C_{2}=\frac{\frac{1}{3}\left[\frac{1}{3}\left(\frac{\bar{X}_{3: 1}}{\bar{Y}_{3: 1}}\right)+\left(\frac{\bar{X}_{1: 1}}{\bar{Y}_{1: 1}}\right)+3\left(\frac{\bar{X}_{1: 3}}{\bar{Y}_{1: 3}}\right)\right]}{\left(\frac{\bar{X}_{0: 1}}{\bar{Y}_{1: 0}}\right)}
$$

By extending the work of Rao and Pereira (1968), it is easily shown that the variance of this estimator can be estimated using

$$
\begin{aligned}
\operatorname{Var}\left(R \hat{C} C_{2}\right)=\frac{R \hat{C} C_{2}^{2}}{n}\left[\frac { 1 } { 9 R ^ { 2 } } \left[\frac{1}{9}\left(\frac{\bar{X}_{3: 1}}{\bar{Y}_{3: 1}}\right)^{2}\left(\frac{S_{Y_{3: 1}}^{2}}{\bar{Y}_{3: 1}^{2}}+\frac{S_{X_{3: 1}}^{2}}{\bar{X}_{1: 1}^{2}}-\frac{2 S_{X_{3: 1} Y_{3: 1}}}{\bar{X}_{3: 1} \bar{Y}_{3: 1}}\right)\right.\right. \\
+\left(\frac{\bar{X}_{1: 1}}{\bar{Y}_{1: 1}}\right)^{2}\left(\frac{S_{Y_{1: 1}}^{2}}{\bar{Y}_{1: 1}^{2}}+\frac{S_{X_{1: 1}}^{2}}{\bar{X}_{1: 1}^{2}}-\frac{2 S_{X_{1: 1} Y_{1: 1}}}{\bar{X}_{1: 1} \bar{Y}_{1: 1}}\right) \\
\left.+9\left(\frac{\bar{X}_{1: 3}}{\bar{Y}_{1: 3}}\right)^{2}\left(\frac{S_{Y_{1: 3}}^{2}}{\bar{Y}_{1: 3}^{2}}+\frac{S_{X_{1: 3}}}{\bar{X}_{1: 3}^{2}}-\frac{2 S_{X_{1: 3} Y_{1: 3}}}{\bar{X}_{1: 3} \bar{Y}_{1: 3}}\right)\right] \\
+\left(\frac{\left.\left.S_{X_{1: 0}}^{2}+\frac{S_{Y_{0: 1}}^{2}}{{\overline{X^{2}}}_{1: 0}^{2}}\right)\right]}{Y_{0: 1}}\right)
\end{aligned}
$$

where

$$
R=\frac{1}{3}\left[\frac{1}{3}\left(\frac{\bar{X}_{3: 1}}{\bar{Y}_{3: 1}}\right)+\frac{\bar{X}_{1: 1}}{\bar{Y}_{1: 1}}+3\left(\frac{\bar{X}_{1: 3}}{\bar{Y}_{1: 3}}\right)\right]
$$

The estimated bias would be 


$$
\begin{aligned}
\operatorname{BI\hat {A}} S\left(R \hat{C} C_{2}\right)=\frac{R \hat{C} C_{2}}{n}\left[\frac{S_{X_{1: 0}}^{2}}{\bar{X}_{1: 0}^{2}}+\frac{\bar{X}_{3: 1} / \bar{Y}_{3: 1}}{9 R}\left(\frac{S_{Y_{3: 1}}^{2}}{\bar{Y}_{3: 1}^{2}}-\frac{S_{X_{3: 1} Y_{3: 1}}}{\bar{X}_{3: 1} \bar{Y}_{3: 1}}\right)\right. \\
+\frac{\bar{X}_{1: 1} / \bar{Y}_{1: 1}}{3 R}\left(\frac{S_{Y_{1: 1}}^{2}}{\bar{Y}^{2}{ }_{1: 1}}-\frac{S_{X_{1: 1} Y_{1: 1}}}{\bar{X}_{1: 1} \bar{Y}_{1: 1}}\right) \\
+\frac{\bar{X}_{1: 3} / \bar{Y}_{1: 3}}{R}\left(\frac{\left.\left.S_{Y_{1: 3}}^{2}-\frac{S_{X_{1: 3} Y_{1: 3}}}{\bar{Y}_{1: 3} \bar{Y}_{1: 3}}\right)\right]}{X_{1: 3}}\right)
\end{aligned}
$$

where $\mathrm{R}$ is defined in (6). If true parameter values are used in the estimates of variance and bias, these are exact to order $n^{-1}$.

Further, by including the $3: 1$ and 1:3 ratios, the proposed estimator should be more sensitive to competition. Because replacement series experiments are typically conducted using all five ratios, it would be logical to make use of all information collected.

In the numerator, $\bar{X}_{3: 1} \bar{Y}_{3: 1}$ is divided by 3 because there are 3 parts of $X$ to every part of $\mathrm{Y}$, requiring the biomass of $\mathrm{Y}$ to be multiplied by 3 to be comparable to that of $X$. Similar reasons can be given for the coefficients of the remaining terms in the numerator. The average in the numerator should theoretically be 1 if competition is not present. Likewise, the denominator should also be 1, resulting in an RCC of 1 when no competition is present.

To date, no test of the hypothesis $\mathrm{H}_{0}: \mathrm{RCC}=1$ vs. $\mathrm{H}_{1}: \mathrm{RCC} \neq 1$ has been presented in the biological literature. Therefore, there is no basis to determine whether an estimate of RCC is significantly different from 1 . Two methods of testing this hypothesis will be proposed.

First consider the construction of a z-statistic of the form

$$
\hat{z}=\frac{R \hat{C} C-1}{\sqrt{\operatorname{Vâr}(R \hat{C} C)}}
$$

Although (8) is the form of a t-statistic, it is not obvious how many degrees of freedom are associated with the statistic, leading us to consider it as a $\mathrm{z}$-statistic. However, because the estimated variances of $\mathrm{RCC} \hat{C}_{1}$ and $\mathrm{RCC} \mathrm{C}_{2}$ are highly variable, the effect of this variability on the test is a concern.

5. Data and Simulation

A Monte Carlo study was used to examine the behavior of the z-statistics for both 
estimators. The properties of the test should depend on the means for each species in each of the five ratios and the variance-covariance structure of the populations. To provide realistic values for these parameters, numerous replacement studies were reviewed. From these, four were selected to provide parameters for the simulation. Two came from the mosquito study. The remaining two came from a study examining the effects of seedcorn maggot (SCM) injury on competition in soybean stands thus impacting development and yield (Higley \& Pedigo, 1990).

Seedcorn maggot larvae feed on germinating soybean plants. This can lead to intraspecific competition between injured and uninjured plants. To study the effect of SCM feeding, replacement series experiments were conducted using an RCBD with four replications. The treatments were in a $4 \times 5$ factorial arrangement with four planting densities $(10,20,30$, and 40 plants/row-m) and 5 ratios $(1: 0,3: 1,1: 1,1: 3$, and 0:1). After thinning the initial planting to the desired density, SCM damage was simulated by excising the plumules of newly emerged plants. The number of plants within a treatment to be injured was determined by the desired ratio of injured to uninjured plants. The estimated parameters from the SCM study are quite different from those in the mosquito study, giving us insight into the behavior of the proposed test in another region of the parameter space.

The mosquito experiment with a high diet and the SCM injury study with 10 plants/row-m each had observed RCC values close to one. The estimated means from these experiments were adjusted slightly so that the RCC values were exactly one. The adjusted means were the population parameters in the Monte Carlo study. The estimated covariances were used as the population parameters in the simulations. The remaining two populations had large RCC values, indicating competition. These population values were taken from the mosquito experiment with a low diet, and from the SCM injury study with 30 plants/row-m. For these two, the estimated means and variance-covariance structure from the studies were the population values in the simulations. The parameters used in the study are presented in Tables 1 to 4 . Because these studies are labor intensive, rarely would resources permit more than eight replicates. Hence, eight replicates were used in the simulation.

The two mosquito experiments and the two SCM studies each gave rise to two cases. Case one utilizes competition means with the competition variance-covariance structure. No-competition means with no-competition variance-covariance structure is the second case. SAS was then used to simulate 1000 samples of size 8 from a normal population with the prescribed set of parameters for each case.

$\mathrm{RC} \mathrm{C}_{1}, \mathrm{R} \hat{\mathrm{C}} \mathrm{C}_{2}$ and the associated z-statistics were calculated for each of the 1000 simulations. The respective $\mathrm{z}$-statistics were compared to 1.96 for a $5 \%$ test and 1.645 for a $10 \%$ test. (See results.)

A bootstrap test was also proposed. 499 resamples were obtained from the original sample in a manner that ensured balance, i.e., each observation was chosen the 
same number of times. This is done in order to reduce simulation error (Davison, et al., 1986). $R \hat{C C} C_{i}$ is computed for the original sample and $R \hat{C} C_{i}^{*}$ computed for each of the 499 resamples. The test is conducted by comparing

$$
|R \hat{C} C-1|>\left|R \hat{C} C^{*}-R \hat{C} C\right|
$$

where

$$
\left|R \hat{C} C^{*}-R \hat{C} C\right|
$$

is the 24th largest difference for a 5\% test and the 49th largest difference for a $10 \%$ test. This eliminates dependence on the sample variance because it is no longer in the denominator of the test statistic (Hall and Wilson, 1991).

Because of its computer intensity, the bootstrap would be more difficult for practitioners to implement. In no case did the bootstrap outperform the z-test so only results of the z-tests will be presented here.

\section{Conclusions}

When comparing the size and power of the z-statistic tests (see Table 5), the alternative estimator, $\mathrm{RCC}_{2}$, is superior to the standard estimator, $\mathrm{RC} \mathrm{C}_{1}$. For the study based on parameters from the SCM experiment, the power is approximately the same for both estimators. However, the size of the test is above the stated level for $\mathrm{RCC}_{1}$ and close to the stated level for $\mathrm{RCC}_{2}$. For the study based on parameters from the mosquito study, the opposite is true. The size of the test is approximately the same and close to the stated level for both estimators, but the power is much greater for the test based on $R \hat{C} C_{2}$ than the one based on $R \hat{C} C_{1}$. These results are not surprising because $R \hat{C} C_{2}$ makes use of more information than does $\mathrm{RCC}_{1}$. The different behavior of the tests for the two studies may be due to differences in the underlying variance-covariance structure.

This is a limited study and further simulations are needed before definite recommendations can be made. Only eight replications were considered here. The behavior of the tests when fewer replications are available needs to be evaluated. The impact of the variance-covariance structure on the size and power of a test seems to be large and needs further investigation.

Use of a bootstrap test does not appear to improve either the size or power of a test when compared to the z-statistics. It may be possible to improve the bootstrap test by using the bootstrap estimate of the sample variance in the denominator. However, based on current results and due to the fact that the bootstrap is very computationally intensive, it is not recommended. 


\section{Acknowledgements}

We wish to thank Gene Boilesen and Linda Pavlish for their programming help on the simulation study.

8. References.

Buonaccorsi, J. P. and A. M. Liebhold (1988). Statistical Methods for Estimating Ratios and Products in Ecological Studies. Environmental Entomology 17: 572-580.

Cochran, William G. (1977), Sampling Techniques, 3rd ed. Wiley: New York.

Davison, A. C., D. V. Hinkley, and E. Schechtman (1986). Efficient bootstrap simulation. Biometrika 73: 555-566.

Hall, Peter, and Susan R. Wilson (1991). Two Guidelines for Bootstrap Hypothesis Testing. Biometrics 47: 757-762.

Harper, John L. (1977). Population Biology of Plants. Academic Press: New York.

Higley, L. G., and L. P. Pedigo (1990). Soybean growth responses and intraspecific competition from simulated seedcorn maggot injury. Agron. J. 82: 1057-1063.

Novak, Mark G., Leon G. Higley, Carl A. Christianssen, and Wayne A. Rowley (1993). Evaluating Larval Competition Between Aedes albopictus and A. triseriatus (Diptera: Culicidae) through Replacement Series Experiments. Environmental Entomology 22: 311-318.

Rao, J. N. K., and Norma P. Pereira (1968). On Double Ratio Estimators. Sankhya, A:30: 83-90.

Smith, T. M. F. (1966). Ratios of Ratios and Their Applications. J. Roy. Stat. Soc., Series A 129: 531-533. 


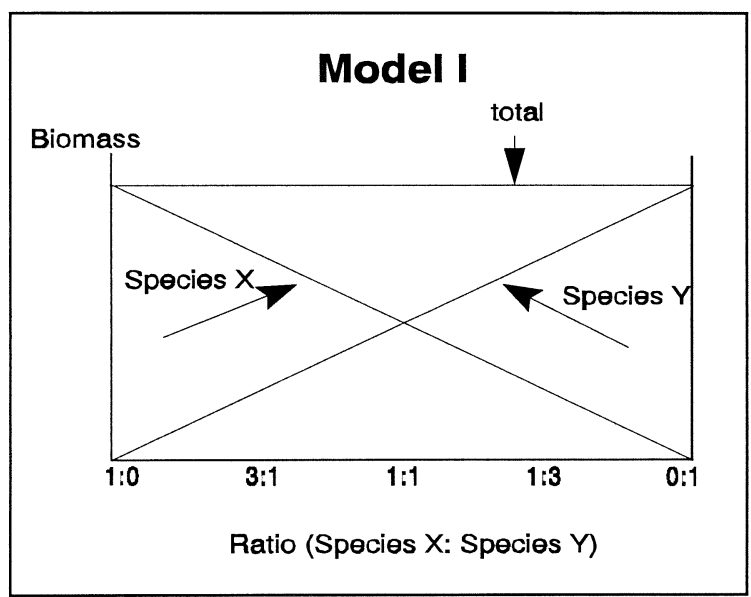

Figure 1

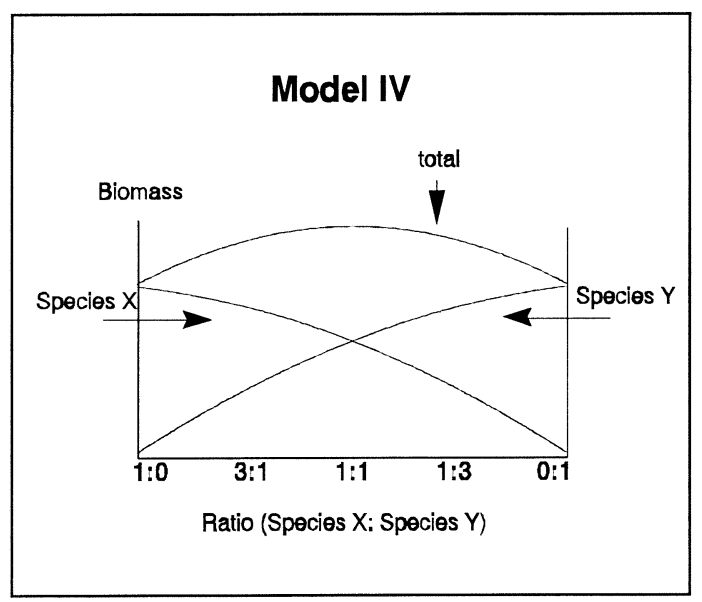

Figure 4

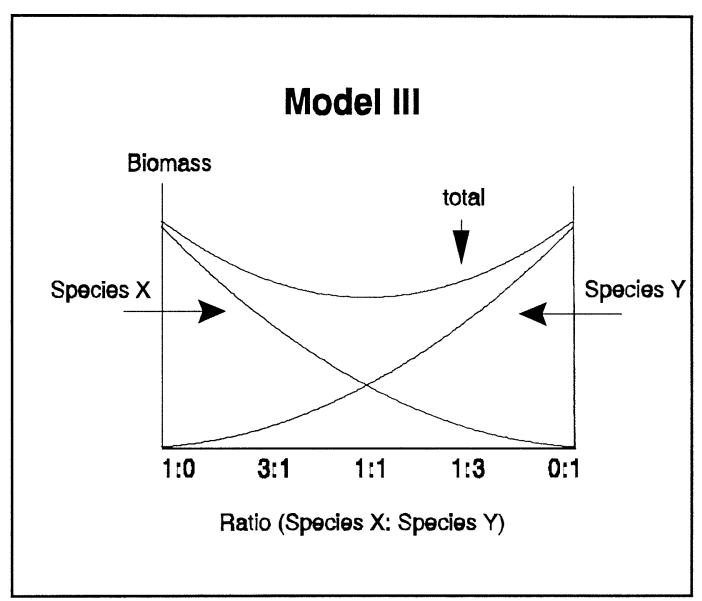

Figure 3

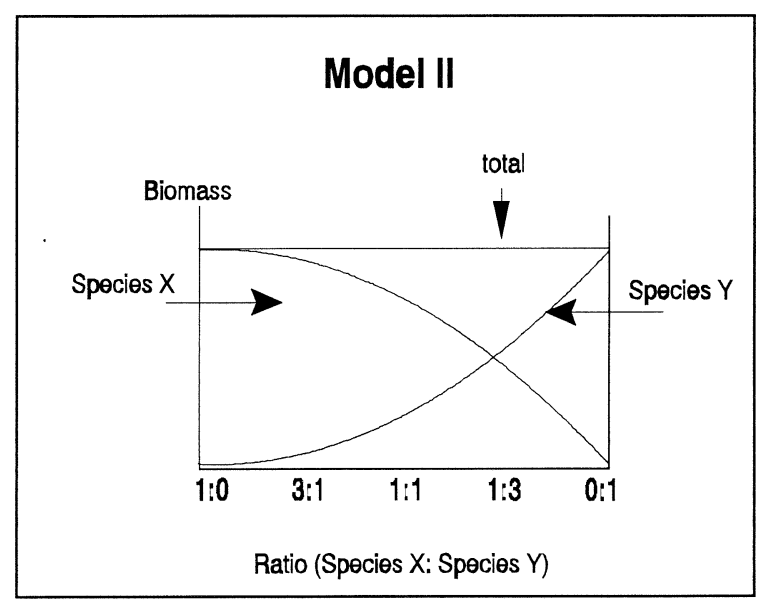

Figure 2

Table 1: Values from mosquito study used as parameters for the no competition case $\left(\right.$ diet $=$ low, $\left.\mathrm{RCC}_{1}=\mathrm{RCC}_{2}=1.0\right)$.

\begin{tabular}{||l|l|l|l|l|l||}
\hline $\mathrm{X}: \mathrm{Y}$ & \multicolumn{1}{|c|}{$\sigma_{\mathrm{X}}{ }^{2}$} & \multicolumn{1}{|c|}{$\sigma_{\mathrm{XY}}$} & \multicolumn{1}{|c||}{$\sigma_{\mathrm{Y}}{ }^{2}$} & \multicolumn{1}{|c||}{$\mu_{\mathrm{X}}$} & $\mu_{\mathrm{Y}}$ \\
\hline $0: 1$ & 0 & 0 & $2.376 \times 10^{-5}$ & 0 & .019495 \\
\hline $1: 3$ & $7.9116 \times 10^{-7}$ & $-2.121 \times 10^{-6}$ & $6.1819 \times 10^{-6}$ & .00521825 & .01462125 \\
\hline $1: 1$ & $8.5461 \times 10^{-6}$ & $-7.119 \times 10^{-7}$ & $2.4651 \times 10^{-6}$ & .0104365 & .0097475 \\
\hline $3: 1$ & $7.6660 \times 10^{-6}$ & $1.4263 \times 10^{-6}$ & $3.6191 \times 10^{-7}$ & .01565475 & .00487375 \\
\hline $1: 0$ & $1.3423 \times 10^{-5}$ & 0 & 0 & .020873 & 0 \\
\hline
\end{tabular}


Table 2: Values from mosquito study used as parameters for the competition case (diet $=$ high, $\mathrm{RCC}_{1}=2.17, \mathrm{RCC}_{2}=3.99$ ).

\begin{tabular}{|l|l|l|l|l|l||}
\hline \hline $\mathrm{X}: \mathrm{Y}$ & \multicolumn{1}{|c|}{$\sigma_{\mathrm{X}}{ }^{2}$} & \multicolumn{1}{c|}{$\sigma_{\mathrm{XY}}$} & \multicolumn{1}{c|}{$\sigma_{\mathrm{Y}}{ }^{2}$} & \multicolumn{1}{c|}{$\mu_{\mathrm{X}}$} & $\mu_{\mathrm{Y}}$ \\
\hline $0: 1$ & 0 & 0 & $2.527 \times 10^{-6}$ & 0 & .009093 \\
\hline $1: 3$ & $1.11047 \times 10^{-7}$ & $-1.193 \times 10^{-7}$ & $1.878 \times 10^{-7}$ & .00579 & .004088 \\
\hline $1: 1$ & $2.92 \times 10^{-6}$ & $4.7564 \times 10^{-6}$ & $9.5019 \times 10^{-6}$ & .009588 & .003215 \\
\hline $3: 1$ & $1.2188 \times 10^{-6}$ & $1.029 \times 10^{-7}$ & $4.489 \times 10^{-8}$ & .010898 & .0003925 \\
\hline $1: 0$ & $1.532^{-6}$ & 0 & 0 & .012523 & 0 \\
\hline
\end{tabular}

Table 3: Values from simulated seedcorn maggot injury on soybean study used as parameters for the no competition case $\left(\mathrm{RCC}_{1}=\mathrm{RCC}_{2}=1.0\right)$.

\begin{tabular}{||l|l|l|l|l|l||}
\hline $\mathrm{X}: \mathrm{Y}$ & \multicolumn{1}{|c|}{$\sigma_{\mathrm{X}}^{2}$} & \multicolumn{1}{c|}{$\sigma_{\mathrm{XY}}$} & \multicolumn{1}{c|}{$\sigma_{\mathrm{Y}}^{2}$} & \multicolumn{1}{c|}{$\mu_{\mathrm{X}}$} & \multicolumn{1}{c|}{$\mu_{\mathrm{Y}}$} \\
\hline $0: 1$ & 0 & 0 & 1.54 & 0 & 3.07 \\
\hline $1: 3$ & 6.95 & -0.12 & 0.83 & 5.7025 & 2.33025 \\
\hline $1: 1$ & 28.16 & -1.87 & 0.27 & 11.405 & 1.535 \\
\hline $3: 1$ & 37.1 & -0.08 & 0.02 & 17.1075 & .7675 \\
\hline $1: 0$ & 74.66 & 0 & 0 & 22.81 & 0 \\
\hline
\end{tabular}

Table 4: Values from simulated seedcorn maggot injury on soybean study used as parameters for the competition case $\left(\mathrm{RCC}_{1}=2.42, \mathrm{RCC}_{2}=2.38\right)$.

\begin{tabular}{||l|l|l|l|l|l||}
\hline $\mathrm{X}: \mathrm{Y}$ & \multicolumn{1}{|c|}{$\sigma_{\mathrm{X}}{ }^{2}$} & \multicolumn{1}{c|}{$\sigma_{\mathrm{XY}}$} & \multicolumn{1}{c|}{$\sigma_{\mathrm{Y}}{ }^{2}$} & \multicolumn{1}{c|}{$\mu_{\mathrm{X}}$} & \multicolumn{1}{c||}{$\mu_{\mathrm{Y}}$} \\
\hline $0: 1$ & 0 & 0 & 13.59 & 0 & 7.46 \\
\hline $1: 3$ & 3.83 & -.28 & .11 & 13.871 & 4.441 \\
\hline $1: 1$ & 33.66 & -.67 & .05 & 26.97 & 2.741 \\
\hline $3: 1$ & 28.13 & -.65 & .11 & 33.88 & 1.1513 \\
\hline $1: 0$ & 158.77 & 0 & 0 & 30.26 & 0 \\
\hline
\end{tabular}


Table 5. Observed size and power for the two measures of competition from the simulation study. For both studies, $\mathrm{RCC}_{1}=\mathrm{RCC}_{2}=1$ when estimating $\alpha$, the size of the test. For the mosquito study, $\mathrm{RCC}_{1}=2.17$ and $\mathrm{RCC}_{2}=3.99$ when estimating $1-\beta$, the power of the test. For the SCM study, $\mathrm{RCC}_{1}=2.42$ and $\mathrm{RCC}_{2}=2.38$ when estimating the power.

\begin{tabular}{||c|c|l|l|l|l||}
\hline \multirow{3}{*}{ Study } & \multirow{2}{*}{$\alpha$} & \multicolumn{2}{|c|}{$\mathrm{RCC}_{1}$} & \multicolumn{2}{c||}{$\mathrm{RCC}_{2}$} \\
\cline { 3 - 6 } & & $\hat{\alpha}$ & $1-\beta$ & $\hat{\alpha}$ & $1-\beta$ \\
\hline \multirow{3}{*}{ Mosquito } & 0.05 & 0.069 & 0.379 & 0.047 & 0.978 \\
\cline { 2 - 7 } & 10 & 0.122 & 0.614 & 0.100 & 0.987 \\
\hline \multirow{3}{*}{$\mathrm{SCM}$} & 0.05 & 0.070 & 0.752 & 0.052 & 0.766 \\
\cline { 2 - 7 } & 0.10 & 0.117 & 0.869 & 0.079 & 0.871 \\
\hline
\end{tabular}

